\title{
Eruptive xanthomas
}

\author{
Joanna Zaremba ${ }^{1,2}$, Andrzej Zaczkiewicz ${ }^{3}$, Waldemar Placek ${ }^{4}$
}

${ }^{1}$ Centre Occupational Medicine Provincial Centre, Wloclawek, Poland

Head of Centre: Joanna Zaremba MD

2Department of Dermatology, Venereal Diseases and Immunodermatology, Nicolaus Copernicus University, Collegium Medicum, Bydgoszcz, Poland

Head of Department: Rafał Czajkowski MD, PhD, DSc

${ }^{3}$ Provincial Clinic of Dermatology for Children and Teenagers, J. Brudziński Provincial Children's Hospital, Bydgoszcz, Poland Head of Clinic: Jarosław Cegielski MSc

${ }^{4}$ Department of Dermatology, Venereal Diseases and Clinical Immunology, University of Warmia and Mazury, Olsztyn, Poland Head of Department: Prof. Waldemar Placek MD, PhD

Postep Derm Alergol 2013; XXX, 6: 399-402

DOI: $10.5114 /$ pdia.2013.39439

\begin{abstract}
Xanthomas are localized lipid deposits in the skin, tendons and subcutaneous tissue associated with lipid abnormality. The hyperlipidemia responsible for this disorder can be caused by a primary genetic defect, a secondary disorder, or both. That kind of skin exanthema may be the first signal of cardiovascular risk. We present a 24-yearold woman with a skin eruption that had appeared a few months earlier.
\end{abstract}

Key words: eruptive xanthomas, lipid abnormality, therapy.

\section{Introduction}

Xanthomas are localized lipid deposits in the skin. They occur in the case of patients with lipid abnormality and are a serious signal of cardiovascular risk.

They are a result of lipoproteins passing through the blood vessel wall into the subendothelial layer, where the lipoproteins are picked up by macrophages. Depending on the types of metabolic disorders, the exanthem may include triglycerides or cholesterol esters [1-5]. The mechanism of accumulation of lipids in skin lesions is similar to the development of atheroma, especially when considering the role of modified low density lipoprotein $(\mathrm{LDL})$ and the way of accumulation of lipids in macrophages [6].

Clinically they are yellowish papules, nodules or plaques. In relation to lesion localization and morphology the following types are distinguished: flat, nodular xanthomas, tendons and joints xanthomas, subdermal xanthomas, seeding xanthomas, nodular-seeding xanthomas, band-shaped xanthomas of the hands and xanthomas of the eyelids $[1,2]$.

Eruptive xanthomas typically appear suddenly as multiple erythematous-yellow, dome-shaped papules on the extensor surfaces of the extremities, buttocks, and hands. They are small (1 $\mathrm{mm}$ to $4 \mathrm{~mm}$ ) [7]. Early lesions may have an erythematous halo and are associated with pruritus and tenderness. A Koebner reaction may occur $[8,9]$.

\section{Case report}

We present a 24-year- old woman who was admitted to the clinic in February 2012 due to numerous scattered yellow papules localized mainly on the lower and upper limbs. The eruption occurred in a very short time after appendectomy (August 2011). The lesions were $2-5 \mathrm{~mm}$ size, dome -shaped and with no subjective complaints (Figures $1 \mathrm{~A}-\mathrm{D}$ ).

Laboratory tests suggested hypercholesterolemia and hypertriglyceridemia, yet with no involvement of abdominal organs.

Tests results from February 2012: total cholesterol level $(\mathrm{CH}) 888,3 \mathrm{mg} / \mathrm{dl}$, high-density lipoprotein level (HDL) 29.5 mg/dl, low-density lipoproteins level (LDL) 381.5 mg/ dl, total triglyceride level (TG) $4412.5 \mathrm{mg} / \mathrm{dl}$, glucose level $94 \mathrm{mg} / \mathrm{dl}$, thyrotropin level (TSH) $1.759 \mathrm{mIU} / \mathrm{ml}$, aspartate aminotransferase level (AST) $19 \mathrm{U} / \mathrm{l}$, alanine aminotranferase level (ALT) $17 \mathrm{U} / \mathrm{l}$, C-reactive protein (CRP) 160.32 $\mathrm{mg} / \mathrm{l}$. Ultrasonography of abdominal: pancreas - homogeneous, not extender, pancreatic duct of Wirsung not enlarged, gallbladder without deposit.

Histopathology of single papules confirmed the presence of numerous foam cells as well as cells of foreign-body type (numerous nuclei placed irregularly in the cell) (Figures 2 and 3).

After clinical diagnosis (preliminarily - combined hyperlipidemia), the oral therapy with statins (ator-

Address for correspondence: Joanna Zaremba, Wojewódzki Ośrodek Medycyny Pracy, 21 Wyszyńskiego St, 87-800 Wloclawek, Poland, phone: +48 601917 099, e-mail: jzaremba1@wp.pl

Received: 1.02 .2013 , accepted: 23.06.2013. 

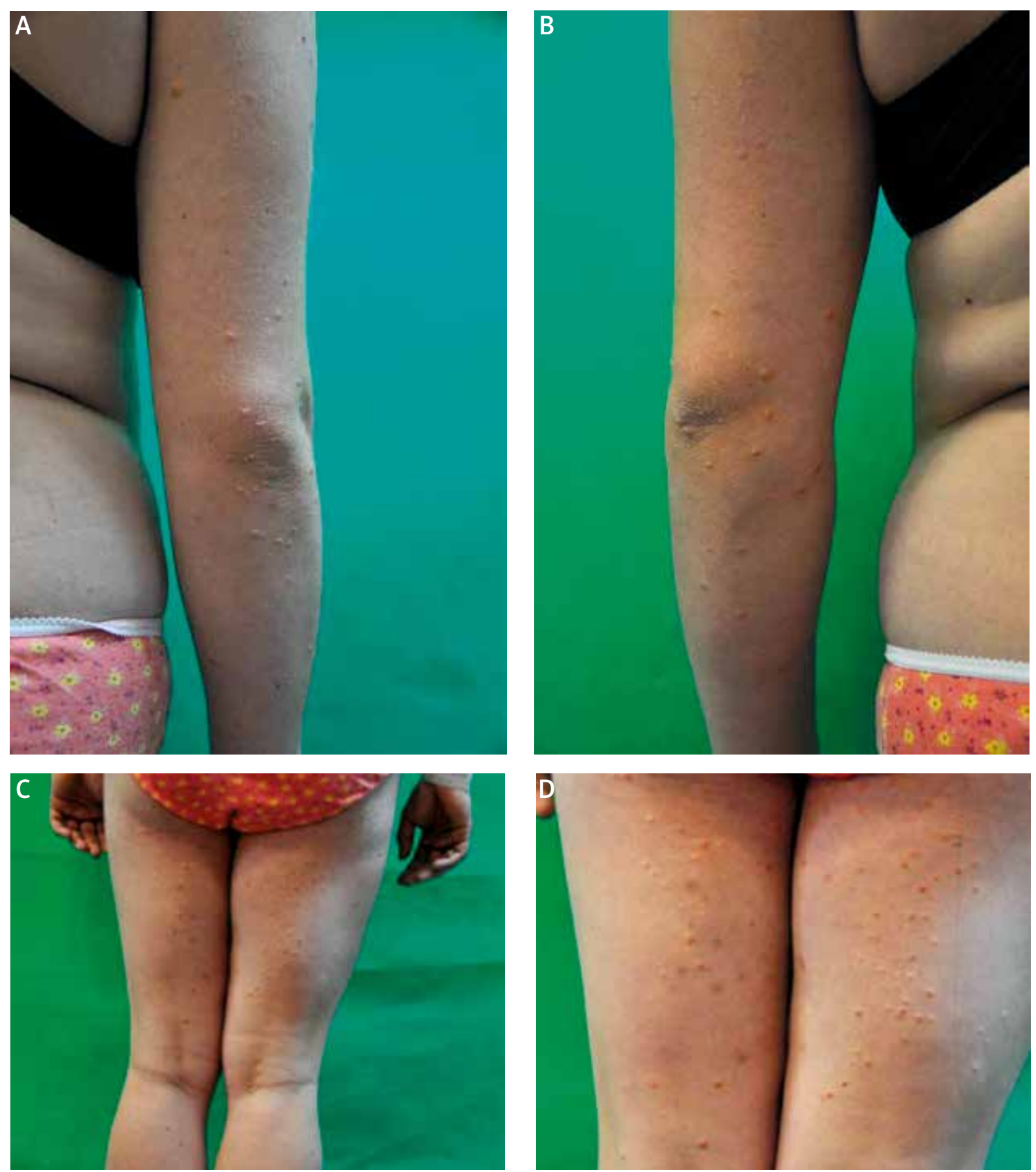

Figure 1 A-D. Clinical picture of lesions

vastatin and rosuvastatin) was started. The patient was also referred to the Clinic of Metabolic Diseases for further diagnosis and combined hyperlipidemia therapy.

As a result of the therapy, the skin lesions cleared up and a gradual normalization of the lipid level in blood serum was obtained. Clinical pictures after the therapy (May 2012) were presented in Figures 4 A-D.
Tests results from May 2012: $\mathrm{CH} 163.3 \mathrm{mg} / \mathrm{dl}$, HDL 33.4 mg/dl, LDL 108.8 mg/dl, TG 105.3 mg/dl. The patient did not use the care of the Clinic of Metabolic Diseases.

\section{Discussion}

Xanthomas are associated with hypertriglyceridemia and congenital chylomicronemia or are an effect of ac- 


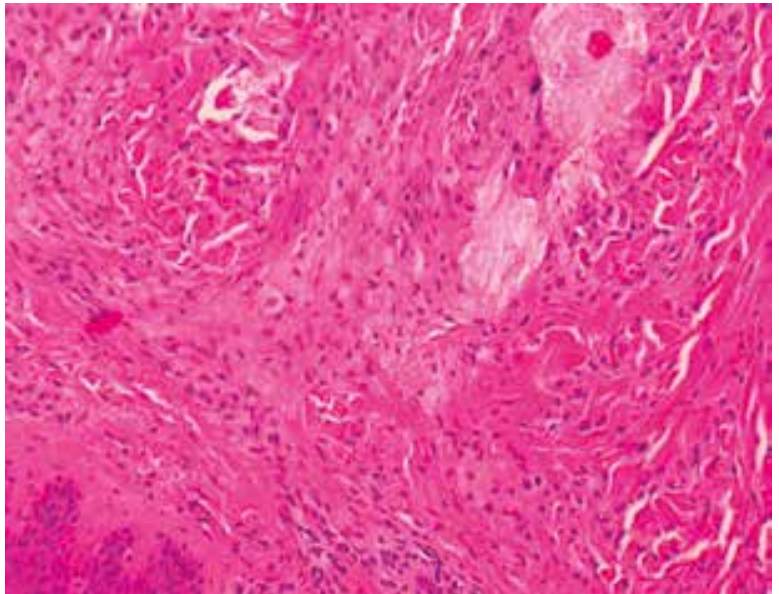

Figure 2. Numerous foam cells
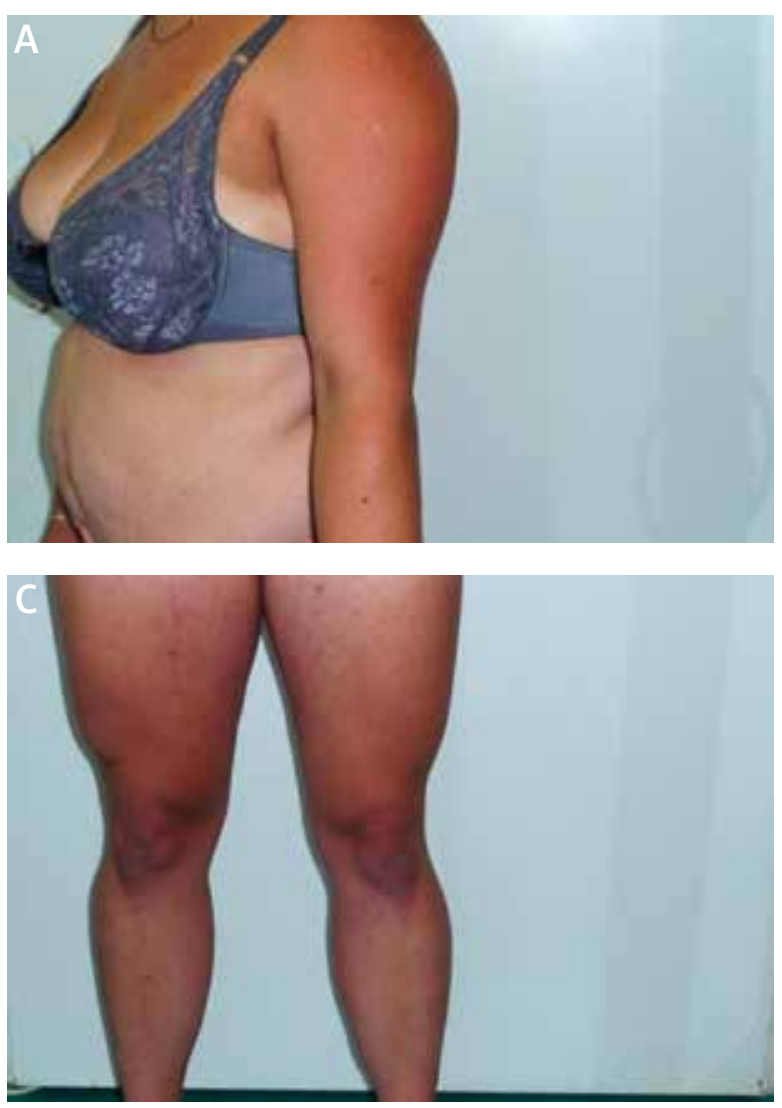

Figure 4 A-D. Clinical picture after therapy

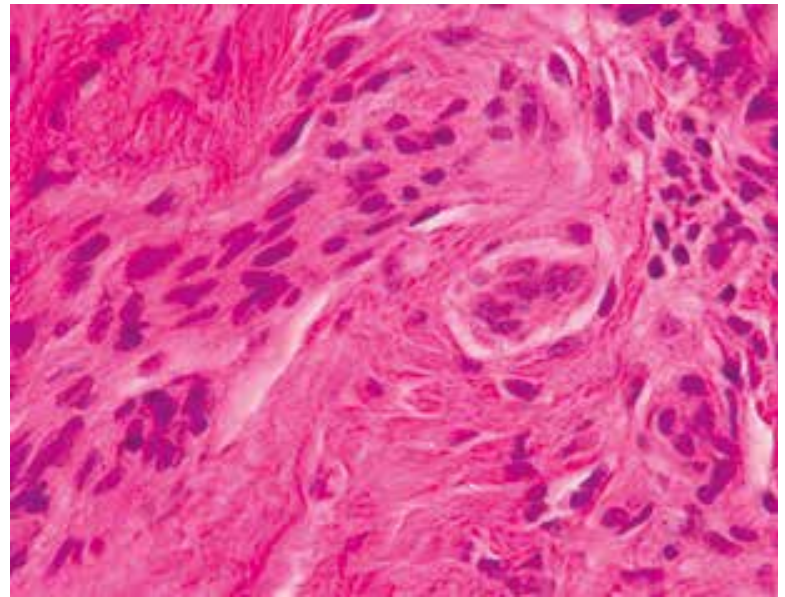

Figure 3. A cell of foreign-body type
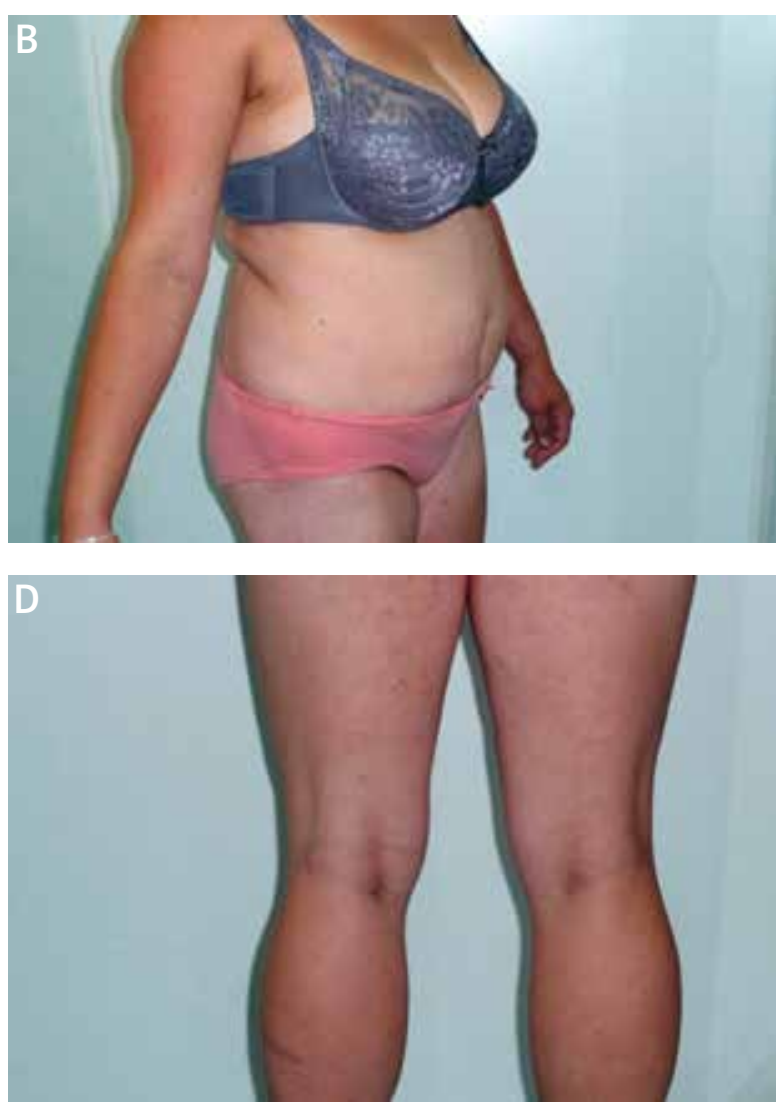

quired hyperlipoproteinemia in the course of such diseases as adult-onset diabetes, hypothyroidism and nephritic syndrome. A therapy with some medicines e.g. retinoids or estrogens, may also result in secondary hyperlipidemia. A few cases of sarcoidosis coexisting with eruptive xanthomas were also described [10].

Lipoproteins are a combination of lipids and proteins. A molecule centre consists of unipolar lipids, non-polar lipids - triglycerides and cholesterol esters. The areola is structured of polar phospholipids, free fatty acids and proteins (apolipoproteins, apoproteins). The elements mentioned are found in different proportions. That defines the density of lipoproteins molecules.

In this connection, on the basis of electrophoresis, 5 main fractions of lipids were distinguished. These are 
chylomicrons, very-low density lipoproteins (VLDL), intermediate density lipoproteins (IDL), LDL and HDL.

The particular fractions are responsible for transportation of exogenic and endogenous triglycerides and of cholesterol.

Lipid metabolism involves proteins of lipoproteins, which are co-factors of enzymes and also such enzymes as lipoprotein lipase, hepatic lipase and lecithin-cholesterol acetyltransferase. The primary genetic defects concerning the apolipoproteins and function disorders of the enzymes mentioned may result in xanthomas [11].

People with normal cholesterol and triglycerides level in blood serum may also have the described cutaneous lesions. It happens in the case of xanthomas which include phytosterols (sitosterolemia, cerebrotendinous xanthomatosis), as well as in the case of people being exposed to endemic injuries [12]. Injury-induced cutaneous lesions mainly occur in the gluteal region, on the limbs on the extensors side and at joints flexions [13-15].

The clinical diagnosis of xanthomas is not usually very difficult. During the differentiation process Xanthoma disseminatum needs to be taken into account. It is a very rare disease of unknown aetiology, where histiocytes proliferation is the essential phenomenon and lipid deposits occur secondarily [11]. Pseudo-xanthomas, spotlike form of histiocytosis from Langerhans cells, storage diseases and even foreign bodies (some implants look like xanthomas in microscope) $[11,12]$ also need to be taken into account.

The therapy always refers to the primary disease. Early therapy which lowers the lipids level in blood serum may withdraw cutaneous lesions. This happened in the case of our patient.

In case when medical treatment does not help, a patient needs to undergo operations: surgery, laser, cryosurgery [1]. Excellent cosmetic results after treatment with the Pulsed Dye Laser, Q-switched Nd-Yag laser and Erbium-Yag laser were described [16-18].

The present case shows how important the role of a dermatologist is in the process of metabolic disease diagnosis. In the case of our patient the tests for hyperlipidemia were done only after dermatologist's medical consultation and the eruption was the first symptom of lipid abnormality.

The early medical treatment has probably prevented a young woman from serious health consequences.

\section{References}

1. Braun-Falco O, Plewig G, Wolf HH, Burgdorf WH.C. Dermatology [Polish]. Czelej, Lublin 2004; 1159-70.

2. Bito T, Kawakami C, Shimajiri S, Tokura Y. Generalized eruptive xanthoma with prominent deposition of naked chylomicrons: evidence for chylomicrons as the origin of urate-like crystals. J Cutan Pathol 2010; 37: 1161-3.

3. Wójcik A, Budzisz E, Rotsztejn H. Skin surface lipids and their measurements. Postep Derm Alergol 2011; 28: 498-505.
4. Barylski M, Małyszko J, Rysz J, et al. Lipids, blood pressure, kidney - what was new in 2011? Arch Med Sci 2011; 7: 105566.

5. Mark L, Paragh G, Karadi I, et al. How can we further improve the LDL-cholesterol target level achievement rate based on the Hungarian MULTI GAP 2011 study results and considering the new European dyslipidemia guidelines? Arch Med Sci 2012; 8: 608-13.

6. Dwivedi S, Jhamb R. Cutaneous markers of coronary artery disease. World J Cardiol 2010; 2: 262-9.

7. Holsinger JM, Campbell SM, Witman P. Multiple erythematous-yellow, dome-shaped papules. Am Fam Physician 2010; 82: 517

8. Merola JF, Mengden SJ, Soldano A, Rosenman K. Eruptive xanthomas. Dermatol Online J 2008; 14: 10.

9. Akhyani M, Daneshpazhooh M, Jafari AK, et al. Koebner phenomenon in xanthelasma after treatment with trichloroacetic acid. Dermatol Online J 2006; 12: 12.

10. Maejima H, Katsuoka K. Sarcoidosis coexisting with ruptive xanthoma. Eur J Dermatol 2011; 21: 298-9.

11. Kaszuba A, Adamski Z. Leksykon dermatologiczny [Polish]. Czelej, Lublin 2011; 226-30.

12. Sterry W, Paus R, Burgdorf W. Zaburzenia metabolizmu lipidów. In: Dermatology [Polish]. Placek W (ed.) Czelej, Lublin 2009; 232.

13. Loeckermann S, Braun-Falco M. Eruptive xanthomas in associacion with metabolic syndrome. Clin Exp Dermatol 2010; 35: 565-6.

14. Pickens S, Farber G, Mosadegh M. Eruptive xanthoma: a case report. Cutis 2012; 89: 141-4.

15. Henning JS, Fazio MG. Yellowish papules on a middle-aged man. Eruptive xanthoma. Am Fam Physician 2011; 83: 73-4.

16. Pietroleonardo L, Ruzicka T. Skin manifestations in familial heterozygous hypercholesterolemia. Acta Dermatovenerol Alp Panonica Adriat 2009; 18: 183-7.

17. Fusade BT. Treatment of xanthelasma palpebrarum by 1064 nm Q-switched Nd:YAG laser: a study of 11 cases. J Dermatol 2008; 158: 84-7.

18. Karsai S, Czarnecka A, Raulin C. Treatment of xanthelasma palpebrarum using a pulsed dye laser: a prospective clinical trial in 38 cases. Dermatol Surg 2010; 36: 610-7. 